\title{
Are We After the Same Thing? Differences among Different MMORPGs Players
}

\author{
Yu-Ling Lin ${ }^{1}$, Hong-Wen $\operatorname{Lin}^{2} \&$ Ya-Cing Jhan ${ }^{2}$ \\ ${ }^{1}$ Department of Business Administration, National Chin-Yi University of Technology, Taiwan \\ 2 Department of Business Administration, National Taiwan University of Science and Technology, Taiwan \\ Correspondence: Yu-Ling Lin, Associate Professor, Department of Business Administration, National Chin-Yi \\ University of Technology, No.57, Section 2, Chung-Shan Road, Taiping, Taichung 411, Taiwan. Tel: \\ 886-4-2392-4505 x. 7784. E-mail: yllin2@ms27.hinet.net/yllin@ncut.edu.tw
}

Received: December 2, 2014

Accepted: December 23, 2014

Online Published: January 5, 2015

doi:10.5430/jms.v6n1p21

URL: http://dx.doi.org/10.5430/jms.v6n1p21

\begin{abstract}
Massively Multiplayer Online Role-playing Games (or MMORPGs) have propelled the vibrant development for the gaming industry and satisfied gamers' desire to play and assume the roles of various virtual characters. In order to explore the differences between the terminal values for different player groups, this study has adopted Means-end Chains theory as the basis for this study and opted for soft laddering as the tool for in-depth interviews to analyze the significance of "game attribute - consequence benefits - terminal values" paths for different player groups. For the purpose of this study, 60 players have been separated into different groups according to their gender, level of education, method of consumption, extent of play and so forth in order to determine the differences in their values. Results of this study revealed that the attributes and consequences for different player groups varied significantly, with Fun and Enjoyment of Life, Warm Relationships with Others, Sense of Accomplishment and Security being the terminal values pursued by the different player groups. This reflects the fact that MMORPGs offer experiences of fun and joy for gamers and also suggest that players want more out of their games.
\end{abstract}

Keywords: means-end chain, laddering method, MMORPGs, group difference

\section{Introduction}

\subsection{Introduce the Problem}

The advancement of internet technologies has enriched the contents and formats of digital games and sparked the vibrant development of the gaming/information industry (Cheng, Kao, \& Lin, 2004). In fact, online games have emerged as the mainstream genre in the industry in 2000 (Chung, 2006). Among the various genres of games available today, Massively Multiplayer Online Role-playing Games (MMORPGs) are the most popular and well-received among gamers (Griffiths, Davies, \& Chappell, 2004a). According to Newzoo (2014), a market research institution for the games industry, the total value of the global games market came to US\$ 75.5 billion in 2013 and it is expected to grow to US\$ 102.9 billion in 2017. The total value of the games market for Asia, Eastern Europe, Latin America and Africa would come to constitute 51\% of the global market. By 2017, it is estimated that approximately US\$ 23.5 billion (approximately 23\%) of the total market value will come from Massively Multiplayer Online (MMO) titles. In terms of Compound Annual Growth Rate (CAGR), the CAGR for the global games industry between 2013-2017 came to 8.9\%. In contrast, the CAGR for the Asian games industry came to $12.1 \%$, which was higher than the global average. More importantly, the CAGR for MMO was actually as high as $13.6 \%$. In addition, according to a survey by Market Intelligence \& Consulting Institute (2014), the scale of Taiwan's online game market is also expected to grow from US\$ 650 million in 2014 to US\$ 732 million in 2017. MMORPGs have managed to draw players to spent significant amount of time in the game environment (Dindar \& Akbulut, 2014). Past studies show that on average, MMORPGs players spend between 22.1 25.8 hours per week on playing their games (Williams, Yee, \& Caplan, 2008; Yee, 2006). These statistics reflect the potential of online games for sustained development and emphasize the fact that online games have become an important part of people's lives.

Griffiths, Davies, and Chappell (2003) pointed out that more than 60\% of MMORPGs players are above the age of 19. Among the gamer population, $33 \%$ are still at school (senior high school - 14\%, college - 14\% and graduate 
school $2 \%$ ) while the distribution of level of education for players who are already in employment is as follows: senior high school $-23 \%$, college graduate $-33 \%$, master degrees $-7 \%$ and doctorate degrees $-2 \%$. In terms of gender, past research indicates that gamers of different genders show significant differences; the percentage of female gamers is $20 \%$ lower compared to male gamers (Griffiths, Davies, \& Chappell, 2004b; Williams et al., 2008; Yee, 2006). This reflects the fact that the bulk of MMORPGs players consists of male players primarily. However, Hussain and Griffiths (2008) also noted that compared to male players, female gamers are more willing to spend more time on playing MMORPGs. These studies show that MMORPGs have extensive player base, with players in different groups having specific differences. Nonetheless, few studies have focused on the association between the attributes of MMORPGs with the specific differences among player groups. Similarly, few studies have attempted to explore the terminal values that different player groups pursue.

The rapid advancement and development of the Internet has sparked intense competition amongst corporations. In order to stay in the game, corporations not only have to constantly revolutionize their management procedures but also embrace "innovation" as the key factor in their strategic planning (Jung, Kim, \& Lee, 2014). Products and services must be able to satisfy consumers' specific needs in order to succeed (Griffin, Price, Maloney, Vojak, \& Sim, 2009). Corporations need to have a clear understanding of the needs of their target consumers in order to be able to define the direction of new product development and formulate marketing strategies with higher precision. With that said, questions such as "What are the game attributes that different groups of players focus on for their preferred MMORPGs titles?" "What consequences/benefits do the attributes have to offer?" and "What consequences enable players to benefit from their desired terminal values?" should be addressed. Therefore, the exploration of different player groups' internal consumption experience and determining the terminal values they pursue have become a vital issue for game developers looking to enlarge the player base for their MMORPGs titles. The Means-ends Chain (MEC) is a useful tool that effectively connects the path between "game attributes - consequence benefits - terminal values" while accounting for the connective psychological process that different player group's experience when playing MMORPGs. Therefore, this study has adopted the MEC to explore the game attributes and consequence benefits that different player groups emphasize and to identify players' terminal values that may be subtle and concealed. The findings will not only serve as a useful reference for the process of game development and design for game developers but also enable game companies to formulate precise marketing strategies for market differentiation in the midst of different player groups.

\section{Theoretical Background}

\subsection{Massively Multiplayer Online Role-playing Game}

MMORPGs are environments that offer newly created virtual worlds and characters (Peterson, 2012) to enable players to engage in continuous interaction with other fellow players through internet connection (Ducheneaut, Yee, Nickell, \& Moore, 2006; Ng \& Wiemer-Hastings, 2005; Sharp \& Rowe, 2006). Through the process of gaming, players are able to control their characters to fulfill various game objectives at both the individual and social level (Yee, 2006). The "visit" function that MMORPGs provide offer ample opportunities for players to get in touch with other players (Williams et al., 2008). Apart from family and work, MMORPGs have become the "third place" for players (Steinkuehler \& Williams, 2006).

The social aspect of MMORPGs is the primary reason (Griffiths et al., 2004a; Yee, 2006) that has made MMORPGs more and more popular by connecting players from around the world to game together (Williams et al., 2008). It is also the very attribute that has drawn different types of gamers to the genre. The competition and cooperation between gamers is the core of the MMORPGs and social interactivity has become a crucial component of MMORPGs (Christou, Law, Zaphiris, \& Ang, 2013; Steinkuehler, 2006; Taylor, 2006). Through joint participation in the gaming process, players were able to engage in group activities/learning, which enable them to fulfill their fantasies and entertain themselves (Castronova, 2005; Juul, 2005; Murray, 2006). De Souza, e Silva, and Roazzi (2010) also argued that the participation in MMORPGs would enable players to perform better in mathematical logic and gain better learning techniques. MMORPGs offer vast possibilities for players to develop various skills such as role playing, learning, self-reflection and self-recognition (Consalvo, 2008).

According to $\mathrm{Ng}$ and Wiemer-Hastings (2005), gaining level, earning loots and getting the recognition and admiration of other players has become the main draw of MMORPGs for many players while $\mathrm{Wu}, \mathrm{Li}$, and Rao (2008) found various attributes of games, such as story plot, visual presentation, depth of game play and control to be highly correlated to player enjoyment. This implies that if players perceive gaming to be a pleasant experience, games could therefore induce motivation for entertainment, positive experience or positive psychological process, such as happiness, playfulness, sociability, and satisfaction (Chiang, Lin, Cheng, \& Liu, 2011; Chou \& Ting, 2003; Vos, van 
der Meijden, \& Denessen, 2011). On the other hand, although players' individual behaviors in the virtual world of games often mirror their behavior in reality, certain aspects of the virtual environment could cause players to show deviant behaviors and even prompt them to commit criminal offenses in the real world (Bayraktar \& Amca, 2012). Mehroof and Griffiths (2009) identified six major characteristics for MMORPGs: "Intermediary Play": enables gamers to play by assuming specific roles in the game; "Growth": enables gamers to accumulate virtual wealth, levels, equipment and experience points; "Permanence": design of MMORPGs typically does not include an ending condition; "Interactivity": enables players to form groups and organizations through in-game communications; "Continuation": stopping play will not prevent the game from going on and "Substance": MMORPGs have physical environments with both temporal and spatial elements.

Past research that focused on factors such as addiction to gaming (Chen \& Park, 2005; Mehroof \& Griffiths, 2009; Stetina, Kothgassner, Lehenbauer, \& Kryspin-Exner, 2011), gamer's personality traits (Anderson \& Bushman, 2001; Lo, Wang, \& Fang, 2005), gamer satisfaction and loyalty (Teng, 2010), game design elements (Song \& Lee, 2007; Lo \& Wen, 2010), online game consumer and conversion (Hsu \& Lu, 2007), commercial activities in virtual games (Papagiannidis, Bourlakis, \& Li, 2008) and so forth did not explore gamers' internal targets and values. In this study, the discussion of "game attribute - consequence benefit - terminal value" structure for different player groups should serve as a valuable supplement to existing studies on online games.

\subsection{Means-end Chains}

Formulated by Gutman (1982) as shown in Figure 1, MECs is often used to explore how consumers associate significant meanings to specific product or service (Voss, Gruberb, \& Szmigin, 2007). MEC is presented as the connection of three variables: the "consequences" and "values" that users derive from specific product "attributes". The chain connections between the variables may be used to explain the reasons behind users' decisions and as such, MECs is a popular method of analysis that has been used to analyze consumption behaviors and values (Olson \& Reynolds, 1983; Walker \& Olson, 1991; Gutman, 1997). "Means" may refer to users' perception of their preferred items, activities or products and may encompass tangible traits or intangible qualities (i.e., product attributes). On the other hand, "End" refers to high level goals (i.e., consequences and values) that individual users seek to achieve through specific product attributes (Olson \& Reynolds, 2001).

A typical MEC model can be represented as a tiered structure of awareness based on consumers' knowledge of a product and self-knowledge (Walker \& Olson, 1991) and it operates on four hypotheses. First, a MEC model assumes that goals and values affect users' decision-making process. Second, it assumes that users would follow and track product differences through categorization or classify products into different grades in order to make sophisticated choices. Third, it assumes that consumer behaviors lead to specific consequences despite the fact that the consequences may not be desirable for all users. Finally, the model makes the assumption that consumers would learn to associate specific consequences with specific behaviors (Gutman, 1982; Coolen \& Hoekstra, 2001).

For this research, MEC turns the variables into attributes of specific products/services, the consequence benefits and the terminal values that users look for (Olson \& Reynolds, 1983; Walker \& Olson, 1991). Under this framework, product attribute is perceived by the users as a means to achieve their goal of terminal values and the consequence benefits and values brought forth by said goal can be defined as the values perceived by the users through the aforementioned attribute (Reynolds \& Olson, 1998; Peter \& Olson, 2009).

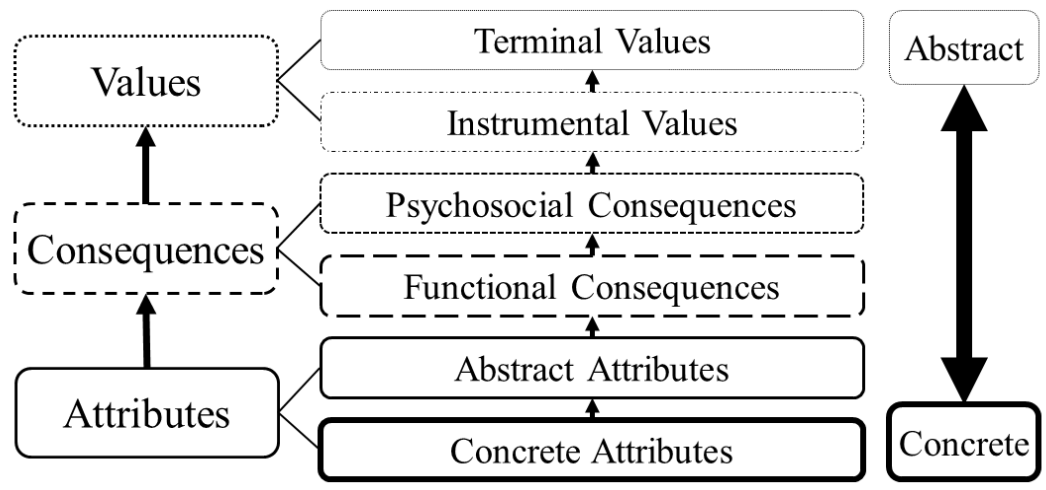

Figure 1. Means-end chains model

Source: Olson \& Reynolds, 1983; Walker \& Olson (1991) 


\section{Methodology}

\subsection{Research Procedure}

In order to construct the value framework of "game attribute - consequence benefit - terminal value" for players of different groups, the research has chosen Laddering as the tool of interview and data collection, followed by Content Analysis for data analysis and semantics summarization. The next step involves the use of Implication Matrix to present the correlation between the variable chains and lastly, Hierarchical Value Map (HVM) is used to summarize the structural difference of values between each group.

First and foremost, laddering is a technique proposed by Reynolds and Gutman (1988) with the purpose of guiding interviewees through the process of constructing their "attribute - consequence - value" structure (Jusan, 2007). With the MEC as the theoretical basis, laddering enables the researcher to understand consumers' motivation for purchase and choice (Sorensen \& Askegaard, 2007). In addition to being commonly used for data collection in MEC studies, the technique is also one of the earliest methods used by psychologists to explore subjects' internal values and faith (Hawlev, 2009). Conducted in a face-to-face, one-on-one, in-depth and semi-structuralized format, laddering is an interviewing technique that has been used to determine how consumers convert specific product attributes to consequences of important meaning for themselves (Bourne \& Jenkins, 2005; Costa, Dekker, \& Jongen, 2004). Through direct prompts, interviewers are able to gradually understand how users utilize the consequence benefits of specific product attributes and the target values derived from those consequences so as to determine the correlations of the chains (Hofstede, Audenaert, Steenkamp, \& Wedel, 1998; Peter \& Olson, 2009). For the purpose of this study, soft laddering (the approach that allows interviewees to answer freely and thereby enables interviewers to achieve in-depth understanding of users' terminal values) has been chosen as the method of data collection.

Next, systematic and objective categorization of trivial and sophisticated interview data was made possible with Content Analysis so as to simplify the content of relevant data prior to the extraction and quantification of vital information (Kassarjian, 1977). After laddering interviews were completed, Content Analysis was used to categorize all the key words and phrases mentioned by interviewees for systematic coding and categorization.

The next step of the research involved the use of Implication Matrix to summarize all the chains that were brought up during the interviews. HVMs were illustrated based on the number of connections between the variables after a quantification process (Reynolds \& Gutman, 1988). In the Implication Matrix, greater values signify stronger connection between two variables and vice versa.

Last, HVM not only offers a clear view of users' value perception structure (Reynolds \& Gutman, 1988) but also presents a comprehensive picture of players' "game attribute - consequence benefit - terminal value" structure. However, if all connections were accepted as valid ones, the resulting HVM would be overly sophisticated and unwieldy to offer a concise representation of the important connections that MMORPGs players were truly concerned with. Establishing a cutoff value is essential. Past research suggested that with a sample size of 50 and 125 value ladders, setting the cutoff value at 4 could account for as much as $2 / 3$ of the important correlations (Reynolds \& Gutman, 1988). And as such, this study has set the cutoff value at 4 as the basis for the analysis of player groups of different genders, level of education, extent of play and consumption style.

\subsection{Samples}

Past studies indicate that approximately $81 \%$ of adults between ages 18-29 play PC games frequently or occasionally (Lenhart, Jones, \& Macgill, 2008), and the majority of MMORPGs players fall between ages 24.77 - 31.16 (Griffiths et al., 2004a; Qian, 2010; Williams et al., 2008; Yee, 2006). In order to ensure sample validity for this study, MMORPGs players between ages 18-30 have been chosen for this study. Since qualitative require in-depth deliberation, having rich and suitable sample data would be more important than having a large sample size. Therefore, the laddering interviews require more than 20 respondents (Reynolds, Dethloff, \& Westberg, 2001) and this study has interviewed a total of 60 (with male and female respondents constituting approximately $50 \%$ of the samples each). To ensure accurate interpretation of the ACV path structure that respondents value, the subjects must have the capacity to convey abstract thoughts with clarity. And as such, the bulk of the respondents are mostly undergraduates $(56.67 \%)$ and graduate students $(43.33 \%)$. In addition, $56.67 \%$ of the respondents spend less than 3 hours per day on gaming on average while the remaining $43.33 \%$ spend more than 4 hours on gaming. $55 \%$ of the respondents play free-to-play (F2P) titles and the remaining $45 \%$ play pay-to-play titles (as shown in Table 1).

Interviews were conducted in accordance with the focus on face-to-face, one-on-one, in-depth and semi-structural format as proposed by Bourne and Jenkins (2005) with durations controlled between 30 to 60 minutes per session. In order to effectively construct player's "game attribute - consequence benefit - terminal value" structure effectively, 
the following questions were presented to the respondents during the interview in the following order: (1) What attributes and features would you consider when playing a MMORPGs? (2) What consequence or benefit do you expect to derive from the attribute/feature? (3) What values can you get from this consequence/benefit? According to previous studies, ladder interviews should stop when the interviewee responds with the value tier or could not provide further information when faced with a series of questions from the interviewer (Klenosky \& Saunders, 2007). Therefore, when a respondent completes a full ladder chain, the interviewer will repeat the aforementioned questions until the respondent is unable to offer anymore valid answers or respond with utterances such as "That's all" or "I don't know", at which point the interview would end.

Table 1. Demographics of participants

\begin{tabular}{llll}
\hline Subject & Item & Frequency & Percent \\
\hline Gender & Male & 31 & 51.67 \\
& Female & 29 & 48.33 \\
Age & $18-20$ & 7 & 11.67 \\
& $21-25$ & 49 & 81.67 \\
\multirow{2}{*}{ Education } & $26-30$ & 4 & 6.66 \\
& Graduate & 26 & 43.33 \\
Games cost (Every month) & Undergraduate & 34 & 56.67 \\
& Free to play & 33 & 55 \\
Playing time (everyday) & Pay to play & 27 & 45 \\
& Below 3 hours & 34 & 56.67 \\
& More than 4 hours & 26 & 43.33 \\
\hline
\end{tabular}

\subsection{Coding and Paths}

After multiple discussions, the research established specific categorization rules for attributes, consequences and values, which were then used for coding purposes. In this study, a total of 12 attributes, 12 consequence benefits and 9 values were identified and categorized (as shown in Table 2). For value variables, three tools are most commonly used for the measurement of individual value theories, namely the Rokeach Value Survey (RVS, proposed by Rokeach in 1973); the Values and Lifestyle Segmentation (VALS, proposed by Mitchell in 1983) and List of Values (LOV, proposed by Kahle in 1983). Kahle's LOV contains 9 core values (self-fulfillment, excitement, fun and enjoyment of life, self-respect, being well respected, sense of belonging, warm relationships with others, sense of accomplishment, security) (Joubert \& Mabunda, 2007) and the theory is closely related to users' daily lives. And as such, it does not require adjustment as time passes. Coupled with the fact that many past MECs studies adopted the LOV theory, this study has therefore adopted LOV as the basis of terminal value classification for MMORPGs players.

Table 2. Item codes of the MMORPGs data and frequency

\begin{tabular}{llllll}
\hline Attributes & \multicolumn{2}{l}{ Frequency Consequences } & Frequency Values & Frequency \\
\hline A1 Role Playing & 33 & C1 Enhanced Efficiency & 26 & V1 Self-fulfillment & 13 \\
A2 Leveling Up & 4 & C2 More Insurance & 5 & V2 Excitement & 11 \\
A3 Multiplayer Gaming & 40 & C3 Time Planning & 2 & V3 Fun and Enjoyment of Life & 56 \\
A4 Audiovisual Effect & 25 & C4 Increased Wealth & 7 & V4 Self Respect & 3 \\
A5 Story & 11 & C5 Enhanced Interaction & 43 & V5 Being Well Respected & 4 \\
A6 Independent Play & 18 & C6 More Fun & 25 & V6 Sense of Belonging & 4 \\
A7 Virtual Pets & 1 & C7 Novelty & 15 & V7 Warm Relationships with Others 28 \\
A8 Celebrity Endorsements 1 & C8 Stress Relief & 11 & V8 Sense of Accomplishment & 39 \\
A9 Online Users & 2 & C9 Continued Playing & 5 & V9 Security & 10 \\
A10 Virtual Items & 18 & C10 Winning & 21 & & \\
A11 Anonymous & 3 & C11 Fantasy Fulfillment & 21 & & \\
A12 Interface Design & 12 & C12 Reduce Risk of Death & 6 & & \\
\hline
\end{tabular}

The 60 respondents constructed a total of 168 value ladders (with a total of 335 chains). On average, each respondent mentioned 2.8 ladders (and 5.92 chains). Barring repeated paths mentioned by each respondent during the interviews, 
a total of 103 different paths existed in the 168 value ladders with a discrepancy rate of $61.31 \%$. This figure indicates diverse changes in the paths constructed by the subjects. For this research, paths mentioned by 2 or more subjects have been included for analysis and a number of the paths (as shown in Table 3) were commonly emphasized by the respondents (at a percentage between 1.19 11.9\%) with a total of $54.76 \%$. These figures suggest that common value structures for MMORPGs exist among the respondents.

Table 3. Path rankings

\begin{tabular}{llll}
\hline Rank & Frequency & Percent & Paths \\
\hline 1 & 20 & 11.9 & A3-C5-V7 \\
2 & 6 & 3.57 & A4-C6-V3 \\
3 & 6 & 3.57 & A12-C1-V3 \\
& 4 & 2.38 & A3-C6-V3 \\
& 4 & 2.38 & A4-C8-V6 \\
& 4 & 2.38 & A4-C12-V9 \\
4 & 4 & 2.38 & A6-C10-V8 \\
& 3 & 1.79 & A1-C11-V8 \\
& 3 & 1.79 & A10-C10-V3 \\
5 & 3 & 1.79 & A10-C10-V8 \\
5 & 3 & 1.79 & A12-C1-V8 \\
& 2 & 1.19 & A1-C5-V7 \\
& 2 & 1.19 & A1-C6-V3 \\
& 2 & 1.19 & A1-C7-V1 \\
& 2 & 1.19 & A1-C11-V3 \\
& 2 & 1.19 & A2-C10-V8 \\
& 2 & 1.19 & A3-C5-V6 \\
& 2 & 1.19 & A3-C6-V7 \\
& 2 & 1.19 & A4-C6-V8 \\
& 2 & 1.19 & A4-C7-V3 \\
& 2 & 1.19 & A5-C6-V8 \\
& 2 & 1.19 & A5-C7-V8 \\
& 2 & 1.19 & A6-C1-V1 \\
& 2 & A10-C1-V3 \\
& 2 & A10-C4-V1 \\
& 2 & A10-C4-V3 \\
& & A10-C11-V8 \\
\hline
\end{tabular}

\subsection{Intercoder Reliability}

For the purpose of this research, Intercoder Reliability proposed by Holsti (1969) was adopted for the advantage of ensuring consistent conclusions even when coders performed message trait assessment independently (Lombard, Synder-Duch, \& Bracken, 2002). Intercoder reliability is a highly recommended methodological bulwark against measurement error and incoherent operational definitions in textual analysis (Hayes \& Krippendorff, 2007; Lombard et al., 2002; Neuendorf, 2002). Four researchers were responsible for the classification of variables and steps were taken to ensure consistent opinions amongst the researchers, with intercoder agreement chosen as the standard for reliability assessment. The average intercoder agreement came to 0.631 and the intercoder reliability was at 0.873 (as shown in Table 4). According to Neuendorf (2002), Intercoder Reliability greater than 0.80 is acceptable and thus, this study has valid research reliability.

Table 4. Intercoder reliability

\begin{tabular}{llcc}
\hline Researcher & $\mathrm{A}$ & $\mathrm{B}$ & $\mathrm{C}$ \\
$\mathrm{B}$ & 0.697 & & \\
$\mathrm{C}$ & 0.606 & 0.758 & 0.606 \\
$\mathrm{D}$ & 0.515 & 0.606 & 0.631 \\
\hline Average of agreement $=(0.697+0.606+0.515+0.758+0.606+0.606) \div 6=0.631$ \\
Reliability $=(4 \times 0.636) \div[1+(4-1) \times 0.636]=0.873$ & \\
\hline
\end{tabular}




\section{Results}

\subsection{The HVM of Different Gender}

The HVM for players of different gender is shown in Figure 2. For the attribute of Interface Design, both male and female players associate the attribute to Enhanced Efficiency. However, male players connect the consequence with the value of Fun and Enjoyment of Life while female players link the consequence with Sense of Accomplishment. This goes to show that players of different genders not only pursue different terminal values from the attribute of Interface Design but also had varying expectations. All players prefer Interface Design with the characteristics of being well-planned, easy to learn, easy to use without requiring players to spend significant amount of time to learn. Male players are not opposed to Interface Design with a variety of functions as long as the interface is easy and smooth to use for a fun and pleasant experience. In contrast, female players tend to suffer from stress during playing due to difficulties with control when faced with an Interface Design that offers diverse functions and in turn lose their inclination to play. In other words, female players seek to affirm their proficiency with games through simple controls, which in turn offer them a Sense of Accomplishment. Second, players in both groups identified the path of "Multiplayer Gaming-Enhanced Interaction-Warm Relationships with Others" as an important chain. Male players are more willing to expand their interpersonal relationships while gaming as they take initiative to make friends through interactions in games and use game-related topics as a tool to foster friendship. Female players, in comparison, are more passive when it comes to expanding their interpersonal network through gaming as they are more inclined to play with their acquaintances and friends. They perceive games as the intermediary tool for fostering friendship and seek to strengthen their friendship bonds through in-game interactions.

Two important paths show gender differences. In the "Role Playing-Fantasy Fulfillment-Sense of Accomplishment" path, male gamers long to experience more excitement through special abilities of the characters they play in the game and to do things they could not do in real life so as to arrive at the terminal value of Sense of Accomplishment. As for female players, they perceive the exaggerated actions performed by game characters to be unrealistic. In contrast, female players demonstrated their emphasis for aesthetics through the chain of "Audiovisual Effect -More Fun -Fun and Enjoyment of Life". Visually appealing graphic designs and styles are more likely to appeal to female players to be more engaged by the game. High degrees of intense excitement from gaming offer little appeal for female players.

Finally, the research discovered that based on the paths created by players of different genders, the value chains for male players all trace back to one single attribute and consequence benefit, meaning that they are "efficiently objective oriented". In contrast, female players connect one single attribute to two consequence benefits (and each consequence benefit in turn connects to two target values, making them more aligned towards "structurally diverse development".
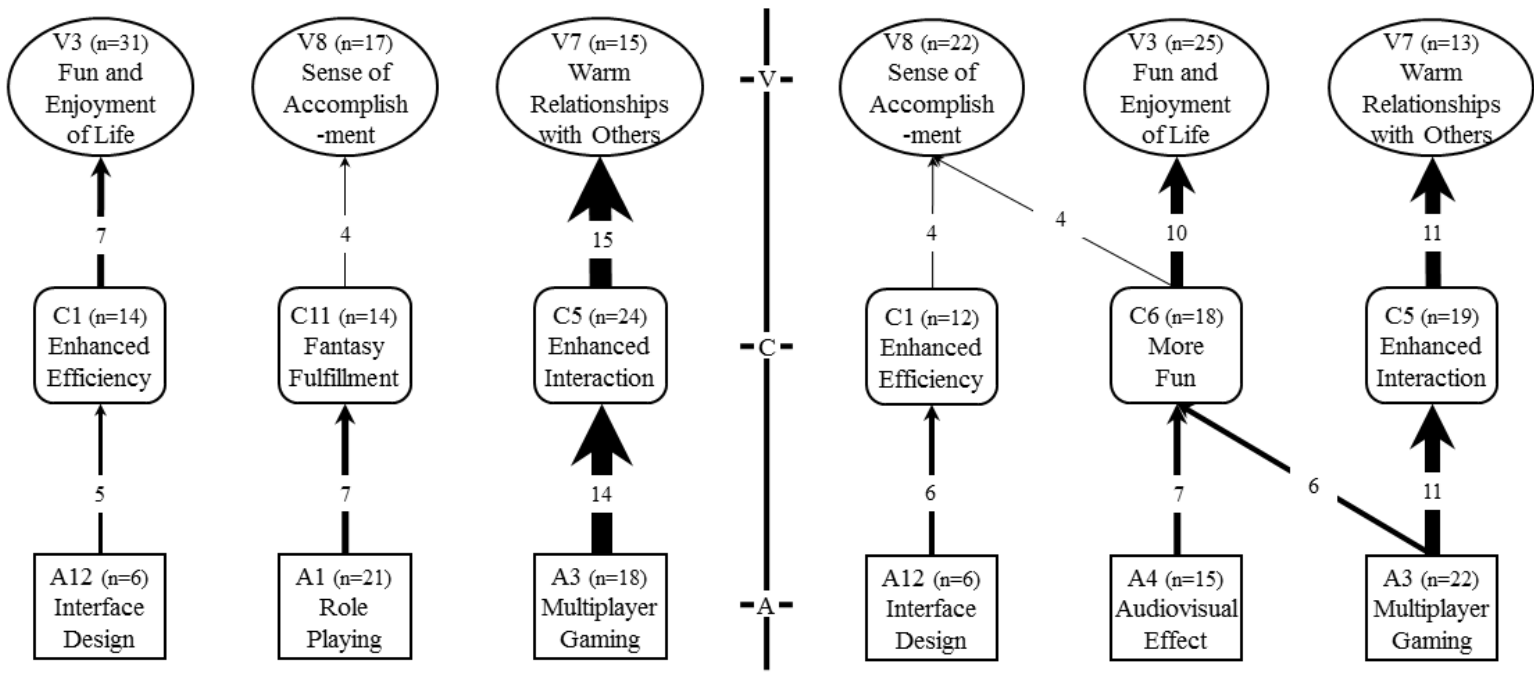

Figure 2. Left: HVM for male participants ( $n=31)$; Right: HVM for female participants $(n=29)($ Cut-off value $=4)$ 


\subsection{The HVM of Different Levels of Education}

The HVM for players of different levels of education is shown in Figure 3. Although graduate student and college student players were after the same values, the two groups did differ in the attributes and consequence benefits they emphasized. First, both player groups emphasized the attribute of Multiplayer Gaming. Graduate student players tend to play with their friends and acquaintances; in addition to creating common topics of conversation, they also sought to foster atmospheres of unity and in turn achieve the consequence of Enhanced Interaction. In contrast, college student players were more inclined to become acquainted with strangers and would try to interact and compete through gaming in order to foster teamwork and thereby achieve Enhanced Interaction. From the consequence, both groups of players arrive at the terminal value of Warm Relationships with Others. Audiovisual Effect is another attribute that mattered to players in both groups. For this attribute, the graduate student players were casually involved; they were after audiovisual simulation and sought to have More Fun through exposure to stunning graphics and great music, ultimately arriving at the value of Fun and Enjoyment of Life. On the other hand, college student players were heavily involved in this attribute; they not only gain More Fun out of the audiovisual experience but also sought Stress Relief, through gaming to further immerse themselves in the game. When they achieve outstanding performance with the characters they play, they would arrive at the terminal values of Sense of Accomplishment and Fun and Enjoyment of Life.

On a related note, most graduate student players remarked that games with simple control designs allow them to save time from having to explore with the controls and thereby offering the consequence of Enhanced Efficiency, which in turn allow them to get a Sense of Accomplishment by being able to play the game with proficiency in short periods of time. Diverse methods of play enable them to get Enhanced Interaction through discussion with others and in turn lead to Warm Relationships with Others. As for college students, they resort to the attribute of Role Playing in the game to interact with others and foster friendship with their peers. Most college students would share and rent Virtual Items in the games to increase the odds of Winning for them and their peers to ultimately arrive at Fun and Enjoyment of Life and Sense of Accomplishment.

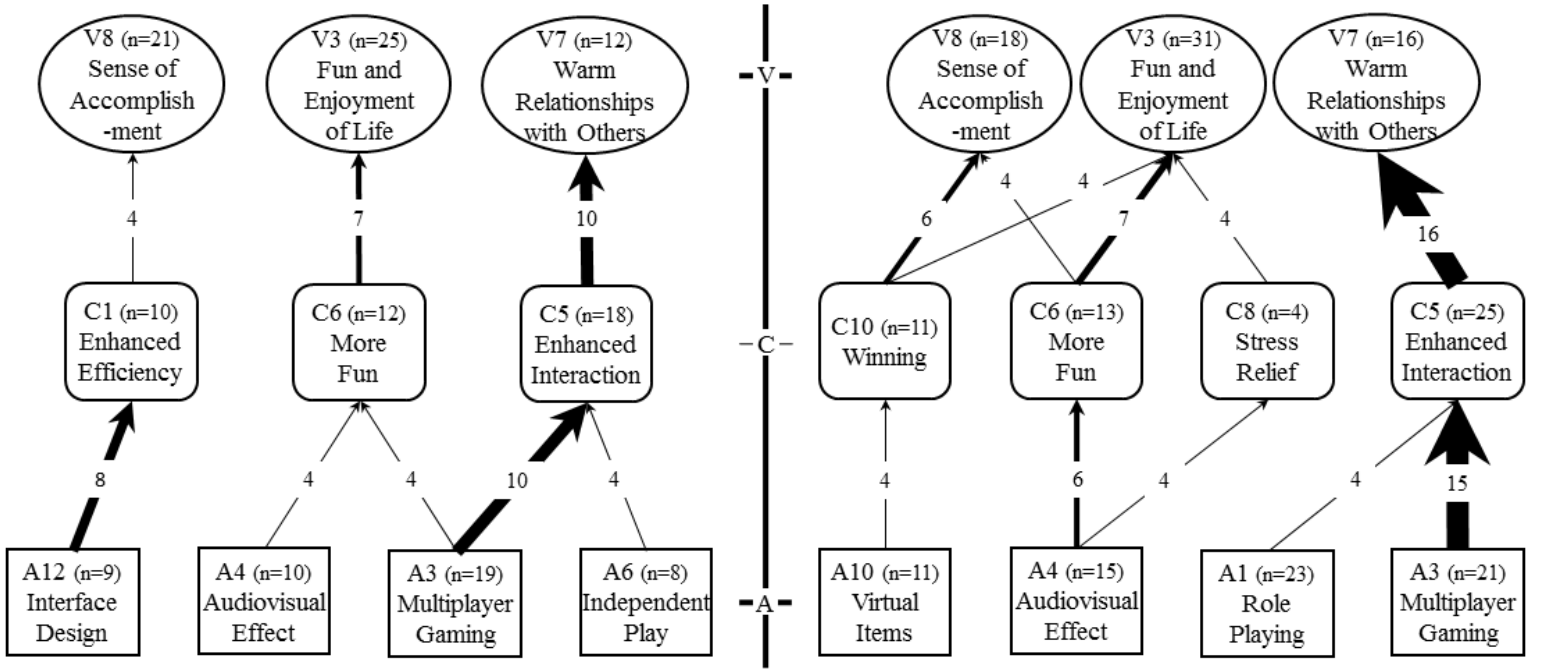

Figure 3. Left: HVM for graduate participants (n=26); Right: HVM for undergraduate participants (n=34) (Cut-off value $=4)$

\subsection{The HVM of Different Consumption Methods}

The HVM for players of different consumption methods is shown in Figure 4. For players in groups of different consumption method, the path "Multiplayer Gaming-Enhanced Interaction-Warm Relationships with Others" carried different significance. Players of pay-to-play games tend to compete and interact with other players in order to get Enhanced Interaction; one could deduce the reason to be the excitement of challenging others in pay-to-play games that will ultimately lead to Warm Relationships with Others. In contrast, players of F2P games simply perceived the games as a medium of interaction with others to create common topics of conversation amongst friends in order to achieve the objective of communication. Despite this difference, for the key path of Interface Design Enhanced Efficiency - Fun and Enjoyment of Life, players of both groups preferred games that are easy to pick up 
and learn so that they would not have to waste time on exploring how to play. The study discovered that, regardless of the method of consumption, when players of both groups found the user interface to be unfriendly or clunky at the initial stage of playing, they would quickly turn their attention to other games in order to find titles that better suit their preferences.

It is also worth mentioning that players of pay-to-play games demonstrate rather extreme behaviors when playing; when their characters are still fairly weak, they would pay for Virtual Items to boost their character powers. As their characters grow stronger, they would still buy Virtual Items to emphasize the superiority of their character strength. Since characters' in-game attributes and abilities have a lasting impact on game development, before pay-to-play players make monetary investments on their game characters, they would be cautious of games that impose caps on character attributes and abilities as it would diminish their anticipated "return" from the game. Pay-to-play players place heavy emphasis on the choice of Role Playing and the purchasing of Virtual Items as these attributes not only offer Enhanced Interaction, Winning and Fantasy Fulfillment through the game but also lead to Warm Relationships with Others and Sense of Accomplishment. Players of F2P games on the other hand emphasized more on entertainment and sought for Audiovisual Effect and Independent Play in their games. In addition to the consequences of More Fun and Winning, they were able to get at the terminal values of Fun and Enjoyment of Life and Sense of Accomplishment.

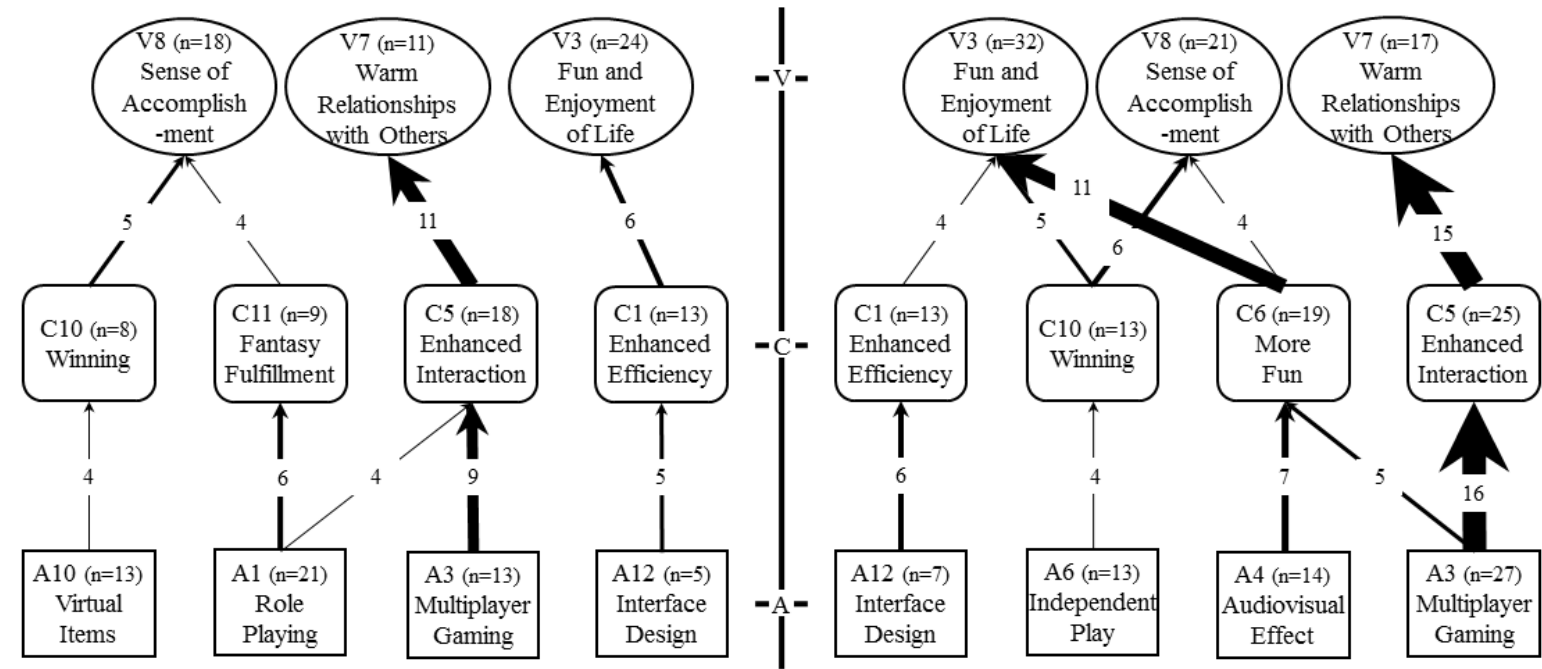

Figure 4. Left: HVM for pay-to-play participants (n=27); Right: HVM for free-to-play participants (n=33) (Cut-off value $=4$ )

\subsection{The HVM of Different Extents of Play}

The HVM for players of different extents of play is shown in Figure 5. Players in both groups look for Fun and Enjoyment of Life, Warm Relationships with Others and Sense of Accomplishment. On top of that, hardcore gamers even sought for Security through gaming. To start, players in both groups identified the key path of "Multiplayer Gaming-Enhanced Interaction-Warm Relationships with Others". For the hardcore gamers, they are more inclined to play with teammates who are more experienced or have more powerful characters. Since they commit significant periods of time to playing the game, they would have more opportunities to cooperate and interact in the game and their topics of conversation would be more deeply related to the crux of the game. Through the process of interaction, these players were able to foster bonds with their peers. On the other hand, most casual gamers were passively engaged in gaming due to invitations from their friends. These players wanted to create topics of conversation through the game and in turn foster Warm Relationships with Others. The path of "Interface Design - Enhanced Efficiency - Fun and Enjoyment of Life" turned out to be another important chain for players of both groups. For this chain, the hardcore gamers emphasized on Enhanced Efficiency, which would offer them more time to hunt more monsters and experience more fun from the game. But for casual gamers, they simply hoped not having to waste time on becoming familiar with the interface and be able to play the game in the shortest amount of time so that they could be rewarded with the feeling of fun and joy.

It is worth noting that the attribute of Role Playing had significantly different consequences for players of different 
extents of play. When hardcore gamers choose their characters in the game, they tend to overlook aspects such as the backstory or mission of the character in the game. Instead, they would go for characters with special abilities that would allow them to avoid or lower the likelihood of character death. This is so that they would feel more secured being immersed in the game. In contrast, casual gamers are willing to play all the characters a game has to offer and enjoy the fun of playing their characters' given roles. Through characters' varying abilities and attributes, the casual gamers were able to realize fantasies that would be impossible in the real world and in turn arrive at the terminal value of Sense of Accomplishment. Last, since hardcore gamers spend longer periods of time playing their games, they are more concerned with the continual development and growth of their in-game characters. And thus, they are likely to rely on Virtual Items that would not only boost various attributes for their characters but also offer greater odds of Winning in different combat or competitions, thereby leading to the terminal values of Sense of Accomplishment and Fun and Enjoyment of Life. In comparison, as casual players spend considerably less time on playing, they focus more on attributes such as Audiovisual Effect and Independent Play that would offer greater degree of entertainment. Through the visual and audio effects of the game, the casual gamers get the consequence of having More Fun and arrive at the value of Fun and Enjoyment of Life. The diversity of play methods available that allow casual players to Win also brought the values of Fun and Enjoyment of Life and Sense of Accomplishment.

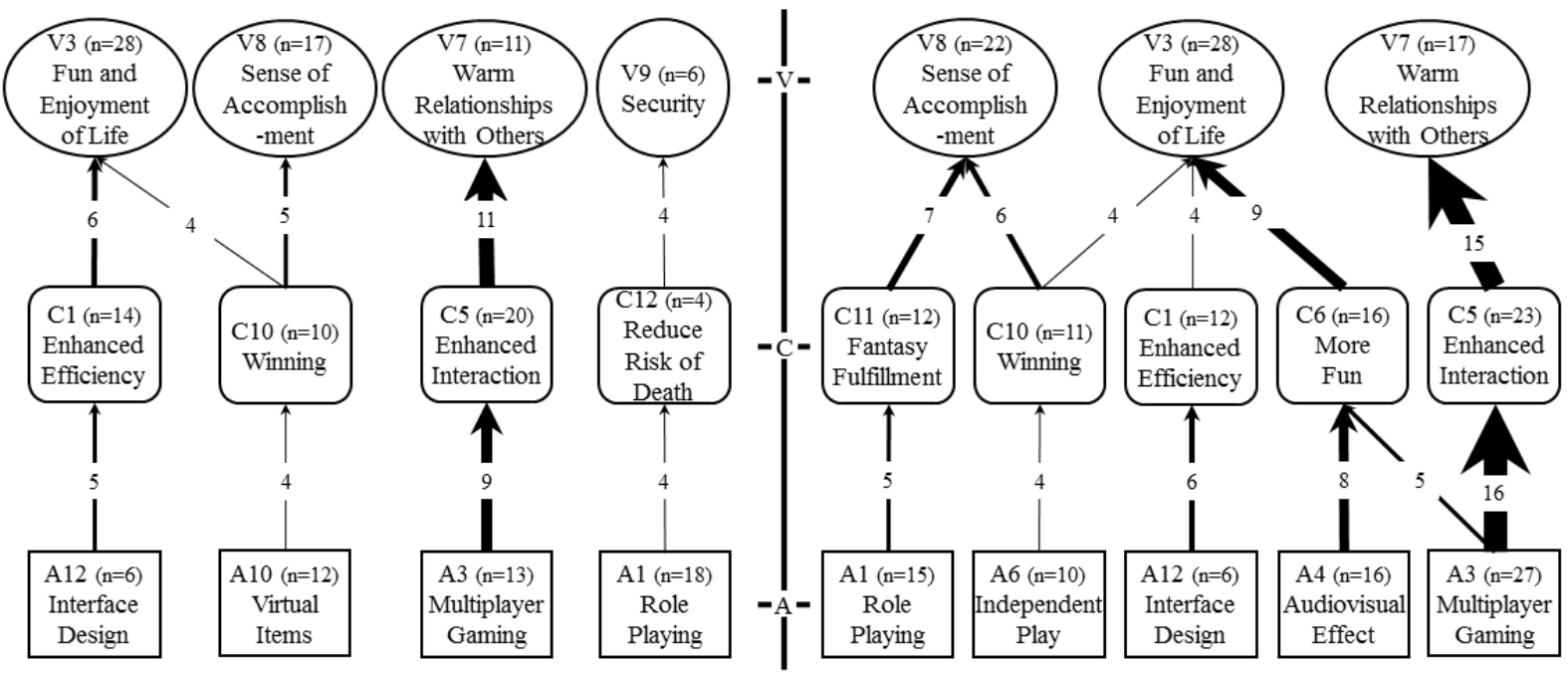

Figure 5. Left: HVM for severe players participants ( $\mathrm{n}=26)$; Right: HVM for mild players participants $(\mathrm{n}=34)$

$($ Cut-off value $=4)$

\section{Conclusions and Implications}

\subsection{Conclusions}

Past studies have conducted detailed statistical surveys on MMORPGs players and covered aspects including players' age distribution, level of education (Griffiths et al., 2003) and extent of play (Griffiths et al., 2004b; Hussain \& Griffiths, 2008; Williams et al., 2008; Yee, 2006). In order to explore the game attributes that different player groups emphasize and the consequence benefits and terminal values they pursue, this study has focused on factors such as gender, level of education, method of consumption and extent of play for group discussions. Results of this study showed that despite pursuing similar terminal values, different player groups emphasized on significantly different game attributes and consequence benefits. This validates the notion that in their pursuit of diverse "goals" (i.e., consequence benefits), MMORPGs players resort to diverse "means" (i.e., attributes).

In terms of gender differences, male players demonstrated more active behavior in making acquaintances with strangers in the attribute of Multiplayer Gaming. In contrast, female players were relatively passive and tend to prefer to play with their friends and peers. For Interface Design, players of both genders look for interfaces that are easy to operate and control, with the caveat that male players have higher acceptance for games with multiple functional buttons. When it comes to Role Playing, male players prefer to take on roles that deviate greatly from the reality while female gamers focus on appealing and cute Audiovisual Effect, which stimulates their interests in playing. 
As for players of different levels of education, for the attribute of Multiplayer Gaming graduate student players are more inclined towards cooperative play while college student players tend to gravitate towards competitive play. Graduate student players experience less stimulation from the excitement of Audiovisual Effect while college student players are more likely to immerse in the games due to the influence of Audiovisual Effect. The sharing and rental of Virtual Items is fairly common in the personal interactions of college student players as the attribute offers greater chances of Winning for them and their teammates.

For players of different consumption methods, players of pay-to-play games tend to prefer competitive play with other players for the attribute of Multiplayer Gaming. Compared with the players of F2P games who simply wanted interactions with other players, players of pay-to-play games sought for more excitement. When faced with unwieldy Interface Design, players in both groups would quickly direct their attention to other games. As for Virtual Items, the attribute offers positive boost in their characters' abilities for players on both ends of the spectrum.

For players of different extents of play, hardcore gamers are more inclined to play with teammates who have more experience in the game or stronger characters when it comes to the attribute of Multiplayer Gaming while casual gamers passively accept invitations from others to take part in the game. Hardcore games also expect more from Interface Design due to their wishes of being able to spend more time on the game. On the other hand, casual gamers simply expect operating interfaces that require minimum amount of learning so as to avoid wasting time. In addition, hardcore gamers' choice for Role Playing emphasizes on characters with abilities that would facilitate the progression of the game, whereas casual gamers enjoy taking on the roles of different characters. Hardcore gamers who spend significant amounts of time on playing place heavy emphasis on the attribute of Virtual Items that would boost their characters' abilities while casual players are content with the entertainment they get from Audiovisual Effect and Independent Play.

\subsection{Implications}

Since male players exhibit a higher degree of acceptance for multifunctional Interface Design (compared to their female counterparts), this study suggests game developers to opt for single-button input in the design of shortcut keys, because players may have difficulty adjusting to shortcut combinations that require simultaneous pressing of two or more buttons. This may in turn cause players to turn to other games rather than spending more time to adapt to the control scheme. Past studies also pointed out that male players prefer to take part in various player activities and PVP events (Yee, Ducheneaut, Shiao, \& Nelson, 2012). Therefore, for the attribute of Multiplayer Gaming which male players emphasize, game developers could incorporate systems of friend-making or come up with a diversity of events. Yee et al. (2012) also observed that when gaming, female players tend to focus on the aspect of exploration. And as such, this study suggest game developers to incorporate systems of friend invitation for female players so that they could explore the world of their game together with their friends. Not only that, game developers could also design more character types oriented towards Fantasy Fulfillment for male players in order to maintain their interests in the game and keep playing. As for the attribute of Audiovisual Effect that female players focus on, game developers can try to include elements such as more adorable characters, soft music and pink colors; games of less sensually stimulating designs (i.e., elements of horror, scares and darkness) usually tend to be more popular among female players.

With regards to player's level of education, this study found that graduate student players are more equipped to take on rational thinking in order to understand and experience the background stories that characters have been given. In addition, graduate student players are more likely to perceive the subtle changes in the game's atmospheres and moods. In order to maintain graduate student players' interests and motivation for playing, game developers could focus on plot-development oriented designs. For college student players, game developers should opt to accommodate to their needs for stimulation. Games with clever use of Audiovisual Effect would help college student players to become more immersed in the storyline. By offering various stimulations at the right moments in the game, college student players would be intrigued by the game, thereby leaving the impression of "the game is incredibly fun" in them, which would create buzz-marketing when they invite their friends to play together.

As for payment schemes, online games today can generally be divided into two categories: pay-to-play and free-to-play (or F2P) (Guo \& Barnes, 2009). The majority of pay-to-play players are driven to achieve better performance in the game through actual monetary investments in the game and they expect more entertainment and excitement from their chosen games. And as such, apart from offering Virtual Items in the games, game developers could also create a comprehensive package of physical services such as exclusive VIP offers or promotional Virtual Items that are only available during press events so that players will be able to benefit from special offers and bonuses outside the game, thereby elevating the value of the game for the players. As for players of F2P games, since they have no trouble getting fun and enjoyment out of their games, extra activities and rewards will have little effect on getting their attention. This study suggests that developers should work on boosting F2P players' sense of 
cohesion in the game as the focus of their game promotion (i.e., through the introduction of community functions such as guilds). Past studies pointed out that when players of the same guild overcome challenges in the game, their co-dependence on one another would grow into a sense of loyalty (Teng, Chen, Chen, \& Li, 2012), which will in turn draw F2P players to continue playing.

As for players of different extents of play, this study suggests game developers to incorporate systems of screening that would enable players to look for teammates meeting specific criteria. This would offer an opportunity for players to get to know one another and enhance the feeling and experience of Multiplayer Gaming. Ducheneaut and Moore (2005) pointed out that high level players tend to be willing to help out players of lower levels; they would not only offer advice on becoming better at the game but also offer actual support in difficult missions. With a player-screening system, players would be able to invite more friends to play through buzz-marketing so that both groups of players would be able to benefit from improved interpersonal interaction through gaming. Typically speaking, most MMORPGs games feature an assortment of items and treasures with varying functions and effects. In terms of Interface Design, Game developers could also incorporate functional buttons that would enable players to switch equipment or modes at any time when needed. For the attribute of Role Playing, this study suggests game developers to further differentiate character attributes and abilities in order to make them more distinct from one another. This would enable hardcore gamers to decide the type of role they wish to take on in the game based on the character archetypes. In addition, this would also satisfy casual gamers' desire to take on the roles of different characters, thereby boosting both group of players' inclination to manage their characters while enriching the game further. Last, Virtual Items have long been the key component of MMORPGs and as such, game developers should work to create new ways to increase the virtual value of treasures and items by incorporating fantastic, rare treasures that players will find worth vying for. The advancement of technology has led players to expect more from the attribute of Audiovisual Effect. To accommodate players' demands, game developers could work on developing 3D titles that will create more immersive virtual environments for players.

\subsection{Future Suggests}

Since the majority of MMORPGs players fall in the 18-30 year-old age group, this study suggests future studies to include working adults in the discussion of differences between MMORPGs players. Second, future studies may also include subjects who have more than 10 years of experience playing online games or professional gamers with experience in large e-sport events to determine the terminal values that experienced MMORPGs seek. For the purpose of this study, soft laddering was chosen as the tool for in-depth interview with MMORPGs players. Follow up studies could use the findings of this research as the basis for large-scale surveys to ensure the structural integrity of attribute, consequence and value chains, which would benefit the discussion of differences among MMORPGs players.

\section{References}

Anderson, C. A., \& Bushman, B. J. (2001). Effects of violent video games on aggressive behavior, aggressive cognition, aggressive affect, physiological arousal, and prosocial behavior: A meta-analytic review of the scientific literature. Psychological Science, 12(5), 353-359. http://dx.doi.org/10.1111/1467-9280.00366

Bayraktar, F., \& Amca, H. (2012). Interrelations between virtual-world and real-world activities: Comparisons of genders, age groups, and pathological and nonpathological internet users. Cyberpsychology, Behavior, and Social Networking, 15(5), 263-269. http://dx.doi.org/10.1089/cyber.2011.0337

Bourne, H., \& Jenkins, M. (2005). Eliciting manager's personal values. An adaptation of the laddering interview method. Organizational Research Methods, 8(4), 410-428. http://dx.doi.org/10.1177/1094428105280118

Castronova, E. (2005). Synthetic worlds: The business and culture of online worlds. Chicago, IL: University of Chicago Press.

Chen, J. V., \& Park, Y. (2005). The differences of addiction causes between massive multiplayer online game and multi user domain. International Review of Information Ethics, 4, 53-60.

Cheng, J. M. S., Kao, L. L. Y., \& Lin, J. Y. C. (2004). An investigation of the diffusion online games in Taiwan: An application of roger's diffusion of innovation theory. Journal of American Academy of Business, Cambridge, $5(1 / 2), 439-445$.

Chiang, Y. T., Lin, S. S. J., Cheng, C. Y., \& Liu, E. Z. F. (2011). Exploring online game players' flow experiences and positive affect. The Turkish Online Journal of Educational Technology, 10(1), 106-114.

Chou, T. J., \& Ting, C. C. (2003). The role of flow experience in cyber-game addiction. CyberPsychology \& Behavior, 6(6), 663-675. http://dx.doi.org/10.1089/109493103322725469

Christou, G., Law, E. L-C., Zaphiris, P., \& Ang, C. S. (2013). Challenges of designing for sociability to enhance 
player experience in massively multi-player online roleplaying games. Behaviour \& Information Technology, 32(7), 724-734. http://dx.doi.org/10.1080/0144929X.2012.754497

Chung, Y. C. (2006). Massively multiplayer online role-playing game-induced seizures: A neglected health problem in internet addiction. CyberPsychology \& Behavior, 9(4), 451-456. http://dx.doi.org/10.1089/cpb.2006.9.451

Consalvo, M. (2008). From dollhouse to metaverse: What happened when the Sims went online. In J. P. Williams, \& J. H. Smith (Eds.), The players' realm: Studies on the culture of video games and gaming. Jefferson, NC: McFarland and Company.

Coolen, H., \& Hoekstra, J. (2001). Values as determinants of preferences for housing attributes. Journal of Housing and Built Environment, 16(3-4), 285-306. http://dx.doi.org/10.1023/A:1012587323814

Costa, A. I. A., Dekker, M., \& Jongen, W. M. F. (2004). An overview of means-end theory: Potential application in consumer-oriented food product design. Trends in Food Science \& Technology, 15(7-8), 403-415. http://dx.doi.org/10.1016/j.tifs.2004.02.005

De Souza, B. B., e Silva, L. X., \& Roazzi, A. (2010). MMORPGS and cognitive performance: A study with 1280 Brazilian high school students. Computers in Human Behavior, 26(6), 1564-1573. http://dx.doi.org/10.1016/j.chb.2010.06.001

Dindar, M., \& Akbulut, Y. (2014). Motivational characteristics of Turkish MMORPG players. Computers in Human Behavior, 33, 119-125. http://dx.doi.org/10.1016/j.chb.2014.01.016

Ducheneaut, N., \& Moore, R. J. (2005). More than just 'XP': Learning social skills in massively multiplayer online games. Interactive Technology and Smart Education, 2(2), 89-100. http://dx.doi.org/10.1108/17415650580000035

Ducheneaut, N., Yee, N., Nickell, E., \& Moore, R. J. (2006). Alone together? Exploring the social dynamics of massively multiplayer online games. In $24^{\text {th }}$ annual CHI conference on human factors in computing systems, Montréal, Québec, Canada.

Griffin, A., Price, R., Maloney, M., Vojak, B., \& Sim, E. (2009). Voices from the field: How exceptional electronic industrial innovators innovate. The Journal of Acceptance of innovation Management, 26(2), 222-240. http://dx.doi.org/10.1111/j.1540-5885.2009.00347.x

Griffiths, M. D., Davies, M. N. O., \& Chappell, D. (2003). Breaking the stereotype: The case of online gaming. CyberPsychology \& Behavior, 6(1), 81-91. http://dx.doi.org/10.1089/109493103321167992

Griffiths, M. D., Davies, M. N. O., \& Chappell, D. (2004a). Demographic factors and playing variables in online computer gaming. CyberPsychology \& Behavior, 7(4), 479-487. http://dx.doi.org/10.1089/cpb.2004.7.479

Griffiths, M. D., Davies, M. N. O., \& Chappell, D. (2004b). Online computer gaming: A comparison of adolescent and adult gamers. Journal of Adolescence, 27(1), 87-96. http://dx.doi.org/10.1016/j.adolescence.2003.10.007

Guo, Y., \& Barnes, S. (2009). Virtual item purchase behavior in virtual worlds: An exploratory investigation. Electronic Commerce Research, 9(1-2), 77-96. http://dx.doi.org/10.1007/s10660-009-9032-6

Gutman, J. (1982). A means-end chain model based on consumer categorization processes. Journal of Marketing, $46(2), 60-72$.

Gutman, J. (1997). Means-end chains as goal hierarchies. Psychology \& Marketing, 14(6), 545-560. http://dx.doi.org/10.1002/(SICI)1520-6793(199709)14:6<545::AID-MAR2>3.0.CO;2-7

Hawlev, M. (2009). Laddering: A research interview technique for uncovering core values. Retrieved from $\mathrm{http} / / / \mathrm{www}$. uxmatters.com/mt/archives/2009/07/laddering-a-research-interview-technique-for-uncovering-corevalues.php

Hayes, A. F., \& Krippendorff, K. (2007). Answering the call for a standard reliability measure for coding data. Communication Methods and Measures, 1(1), 77-89. http://dx.doi.org/10.1080/19312450709336664

Hofstede, F. T., Audenaert, A., Steenkamp, J. B. E. M., \& Wedel, M (1998). An investigation into the association pattern technique as a quantitative approach to measuring means-end chains. International Journal of Research in Marketing, 15(1), 37-50. http://dx.doi.org/10.1016/S0167-8116(97)00029-3

Holsti, O. R. (1969). Content analysis for the social sciences and humanities. Reading, MA: Addison-Wesley Publishing Company.

Hsu, C. L., \& Lu, H. P. (2007). Consumer behavior in online game communities: A motivational factor perspective. Computers in Human Behavior, 23(3), 1642-1659. http://dx.doi.org/10.1016/j.chb.2005.09.001 
Hussain, Z., \& Griffiths, M. D. (2008). Gender swapping and socializing in cyberspace: An exploratory study. CyberPsychology \& Behavior, 11(1), 47-53. http://dx.doi.org/10.1089/cpb.2007.0020

Joubert, J. P. R., \& Mabunda, M. D. (2007). The decision to visit a wilderness area. Southern African Business Review, 11(2), 39-55.

Jung, H. S., Kim, K. H., \& Lee, C. H. (2014). Influences of perceived product innovation upon usage behavior for MMORPG: Product capability, technology capability, and user centered design. Journal of Business Research, 67(10), 2171-2178. http://dx.doi.org/10.1016/j.jbusres.2014.04.027

Jusan, B. M. M. (2007). Identification of user's expectations in mass housing using means-end chain research model. Journal Alam Bina, 9(4), 1-19.

Juul, J. (2005). Half-real: video games between real rules and fictional world. Cambridge, MA: MIT Press.

Kahle, L.R. (1983). Social values and social changes: adaption to life in America. New York, NY: Praeger.

Kassarjian, H. H. (1977). Content analysis in consumer research. Journal of Consumer Research, 4(1), 8-18.

Klenosky, D. B., \& Saunders, C. D. (2007). Put me in the zoo! A laddering study of zoo visitor motives. Tourism Review International, 11(3), 317-327. http://dx.doi.org/10.3727/154427207783948757

Lenhart, A. Jones, S., \& Macgill, A. (2008). Adults and video games. Washington, DC: Pew Internet and American Life Project.

Lo, S. K., Wang, C. C., \& Fang, W. C. (2005). Physical interpersonal relationships and social anxiety among online game players. CyberPsychology \& Behavior, 8(1), 15-20. http://dx.doi.org/10.1089/cpb.2005.8.15

Lo, Y. F., \& Wen, M. H. (2010). A fuzzy-AHP-based technique for the decision of design feature selection in massively multiplayer online role-playing game development. Expert Systems with Applications, 37(12), 8685-8693. http://dx.doi.org/10.1016/j.eswa.2010.06.059

Lombard, M., Snyder-Duch, J., \& Bracken, C. C. (2002). Content analysis in mass communication research: An assessment and reporting of intercoder reliability. Human Communication Research, 28(4), 587-604. http://dx.doi.org/10.1111/j.1468-2958.2002.tb00826.x

Market Intelligence \& Consulting Institute. (2014). Mobile games and entertainment continues to grow. (Chinese version). Retrieved from http://mic.iii.org.tw/aisp/pressroom/press01_pop.asp?sno=356\&type1=2

Mehroof, M., \& Griffiths, M. (2009). Online gaming addiction: The role of sensation seeking, self-control, neuroticism, aggression, state anxiety, and trait anxiety. CyberPsychology \& Behavior, 13(3), 313-316. http://dx.doi.org/10.1089/cyber.2009.0229

Mitchell, A. (1983). The nine American life styles. New York, NY: Warner.

Murray, J. H. (2006). Toward a cultural theory of gaming: digital games and the co-evolution of media, mind, and culture. Popular Communication, 4(3), 185-202. http://dx.doi.org/10.1207/s15405710pc0403_3

Neuendorf, K. A. (2002). The content analysis guidebook. Thousand Oaks, CA: Sage.

Newzoo. (2014). Casual games sector report: Towards the global games market in 2017: A broad look at market growth by screen \& region. (Adobe digital editions version). Retrieved from https://s3.amazonaws.com/CGA_Report/CCNewzooSpringReport-pages.pdf

Ng, B. D., \& Wiemer-Hastings, P. (2005). Addiction to the internet and online gaming. CyberPsychology \& Behavior, 8(2), 110-113. http://dx.doi.org/10.1089/cpb.2005.8.110

Olson, J. C., \& Reynolds, T. J. (1983). Understanding consumers' cognitive structures: Implications for marketing strategy. Advertising and Consumer Psychology, Lexington: Lexington Books, 77-90.

Olson, J. C., \& Reynolds, T. J. (2001). The means-end approach to understanding consumer decision making, understanding consumer decision making: The means-end approach to marketing and advertising strategy. Mahwah, NJ: Lawrence Erlbaum Associates.

Papagiannidis, S., Bourlakis, M., \& Li, F. (2008). Making real money in virtual worlds: MMORPGs and emerging business opportunities, challenges and ethical implications in metaverses. Technological Forecasting \& Social Change, 75(5), 610-622. http://dx.doi.org/10.1016/j.techfore.2007.04.007

Peter, J. P., \& Olson, J. C. (2009). Consumer behavior and marketing strategy ( $9^{\text {th }}$ ed). Boston, MA: McGraw-Hill.

Peterson, M. (2012). Learner interaction in massively multiplayer online role playing game (MMORPG): A sociocultural discourse analysis. ReCALL, 24(3), 361-380. http://dx.doi.org/10.1017/S0958344012000195 
Qian, G. (2010). Psychological perspectives on social behaviors of Chinese MMORPG players. Lecture Notes in Computer Science, 6249, 192-202. http://dx.doi.org/10.1007/978-3-642-14533-9_20

Reynolds, T. J., \& Gutman, J. (1988). Laddering theory, method, analysis and interpretation. Journal of Advertising Research, 28(1), 11-31.

Reynolds, T. J., \& Olson, J. C. (1998). The means-end approach to understanding consumer. Decision marketing and advertising strategy. Mahwah, NJ: Lawrence Erlbaum Associate.

Reynolds, T. J., Dethloff, C., \& Westberg, S. J. (2001). “Advancements in laddering”, understanding consumer decision making: the means-end approach to marketing and advertising strategy. Mahwah, NJ: Lawrence Erlbaum Associates.

Rokeach, M. J. (1973). The nature of human values. New York, NY: The Free Press.

Sharp, C. E., \& Rowe, M. (2006). Online games and e-business: architecture for integrating business models and services into online games. IBM System Journal, 45(1), 161-179. http://dx.doi.org/10.1147/sj.451.0161

Song, S., \& Lee, J. (2007). RETRACTED: Key factors of heuristic evaluation for game design: Towards massively multi-player online role-playing game. International Journal of Human-Computer Studies, 65(8), 709-723. http://dx.doi.org/10.1016/j.ijhcs.2007.01.001

Sorensen, E., \& Askegaard, S. (2007). Laddering: How (not) to do things with words. Qualitative Market Research: An International Journal, 10(1), 63-77. http://dx.doi.org/10.1108/13522750710720404

Steinkuehler, C. (2006). The mangle of play. Games and Culture, 1(3), 1-14. http://dx.doi.org/10.1177/1555412006290440

Steinkuehler, C. A., \& Williams, D. (2006). Where everybody knows your (screen) name: Online games as "third places". Journal of Computer-Mediated Communication, $11(4), \quad 885-909$. http://dx.doi.org/10.1111/j.1083-6101.2006.00300.x

Stetina, B. U., Kothgassner, O. D., Lehenbauer, M., \& Kryspin-Exner, I. (2011). Beyond the fascination of online-games: Probing addictive behavior and depression in the world of online-gaming. Computers in Human Behavior, 27(1), 473-479. http://dx.doi.org/10.1016/j.chb.2010.09.015

Taylor, T. L. (2006). Does WoW change everything? How a PvP server, multinational player base, and surveillance mod scene caused me pause. Games and Culture, 1(4), 318-337. http://dx.doi.org/10.1177/1555412006292615

Teng, C. I. (2010). Customization, immersion satisfaction, and online gamer loyalty. Computers in Human Behavior, 26(6), 1547-1554. http://dx.doi.org/10.1016/j.chb.2010.05.029

Teng, C. I., Chen, M. Y., Chen, Y. J., \& Li, Y. J. (2012). Loyalty due to others: The relationships among challenge, interdependence, and online gamer loyalty. Journal of Computer-Mediated Communication, 17(4), 489-500. http://dx.doi.org/10.1111/j.1083-6101.2012.01586.x

Vos, N., van der Meijden, H., \& Denessen, E. (2011). Effects of constructing versus playing an educational game on student motivation and deep learning strategy use. Computers \& Education, 56(1), 127-137. http://dx.doi.org/10.1016/j.compedu.2010.08.013

Voss, R., Gruberb, T., \& Szmigin, I. (2007). Service quality in higher education: The role of student expectations. Journal of Business Research, 60(9), 949-959. http://dx.doi.org/10.1016/j.jbusres.2007.01.020

Walker, B., \& Olson, J. C. (1991). Means-end chains: Connecting products with self. Journal of Business Research, 22(2), 111-118. http://dx.doi.org/10.1016/0148-2963(91)90045-Y

Williams, D., Yee, N., \& Caplan, S. E. (2008). Who plays, how much, and why? Debunking the stereotypical gamer profile. Journal of Computer-Mediated Communication, $13(4)$, 993-1018. http://dx.doi.org/10.1111/j.1083-6101.2008.00428.x

Wu, J., Li, P., \& Rao, S. (2008). Why they enjoy virtual game worlds? An empirical investigation. Journal of Electronic Commerce Research, 9(3), 219-230.

Yee, N. (2006). The Demographics, motivations and derived experiences of users of massively-multiuser online graphical environments. PRESENCE: Tele-operators and Virtual Environments, 15(3), 309-329. http://dx.doi.org/10.1162/pres.15.3.309

Yee, N., Ducheneaut, N., Shiao, H., \& Nelson, L. (2012). Through the Azerothian looking-glass: Mapping in-game preferences to real world demographics. In Proceedings of the 2012 SIGCHI conference on human factors in computing systems, 2811-2814. http://dx.doi.org/10.1145/2207676.2208683 